
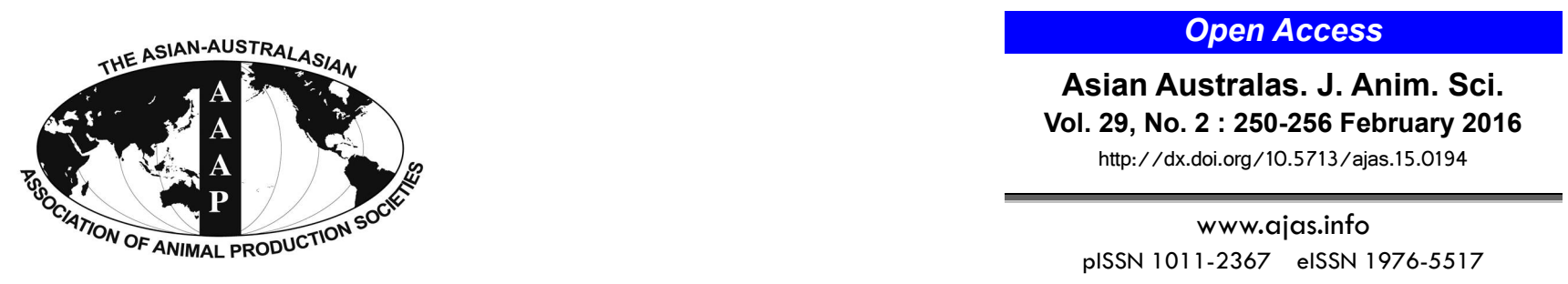

\title{
Effects of Graded Levels of Isomaltooligosaccharides on the Performance, Immune Function and Intestinal Status of Weaned Pigs
}

\author{
X. X. Wang, P. X. Song, H. Wu, J. X. Xue, X. Zhong, and L. Y. Zhang* \\ State Key Laboratory of Animal Nutrition, China Agricultural University, Beijing 100193, China
}

\begin{abstract}
The objective of this study was to investigate the effects of graded levels of isomaltooligosaccharides (IMO) on the performance, immune function and intestinal microflora and intestinal mucosal morphology of weaned pigs. In a 28-day experiment, one hundred eighty, twenty eight-day-old, crossbred (Duroc $\times$ Large White $\times$ Landrace), weaned pigs, with an initial body weight of $8.19 \pm 1.45 \mathrm{~kg}$, were fed either an unsupplemented corn-soybean meal based diet or similar diets supplemented with $0.2 \%, 0.4 \%, 0.6 \%$, or $0.8 \%$ IMO added at the expense of corn. Each treatment was replicated six times with six pigs (three barrows and three gilts) per pen. From day 0 to 14 , weight gain was linearly increased $(p<0.05)$, while gain:feed $(p<0.05)$ was linearly improved and diarrhea rate $(p=$ 0.05 ) linearly declined as the IMO level increased. On d 14, the level of the immunoglobulins $\operatorname{IgA}$, IgM, and IgG in the serum of pigs were linearly increased $(\mathrm{p}<0.05)$ with increasing IMO supplementation. Interleukin-6 (IL-6) was linearly $(\mathrm{p}<0.05)$ and quadratically $(p<0.05)$ decreased as IMO intake increased. From day 15 to 28 , there was a trend for weight gain to be linearly increased, and IL-2 was linearly $(\mathrm{p}<0.05)$ increased as IMO supplementation increased on $\mathrm{d} 28$. Over the entire experiment, weight gain was linearly increased $(p<0.05)$, while gain:feed $(p<0.05)$ was linearly improved and diarrhea rate $(p<0.05)$ was linearly decreased as the IMO level increased. Supplementation with IMO had no effect on the intestinal microflora of pigs in the ileum and cecum of pigs, as well as the villus height and crypt depth in the ileum and jejunum ( $>0.05)$. These results indicate that dietary inclusion of IMO increases weight gain, gain:feed and enhanced the immune status of pigs, and could be a valuable feed additive for use in weaned pigs, particularly during the period immediately after weaning. (Key Words: Immune Function, Intestinal Ststus, Isomaltooligosaccharides, Performance, Weaned Pigs)
\end{abstract}

\section{INTRODUCTION}

Isomaltooligosaccharides (IMO) have an $\alpha \quad 1 \rightarrow 6$ glucosidic linkage in their molecular structure (Kohmoto et al., 1992), and are mainly derived from starch by an enzymatic transgalactosylation reaction (Hayashi et al., 1994; Vetere et al., 2000). Their composition is complex and the degree of polymerization ranges from di- to hexasaccharides (Kaneko et al., 1995b). They typically contain isomaltose, panose, isomaltotriose, and several other branched oligosaccharides made up of four or five glucose residues (Kaneko et al., 1995a).

Isomaltooligosaccharides are widely used in the food industry (Goffin et al., 2011), and have a wide spectrum of

\footnotetext{
* Corresponding Author: L. Y. Zhang. Tel: +86-10-6273-3588, Fax: +86-10-6273-3688, E-mail: zhangliying01@sina.com Submitted Mar. 6, 2015; Revised Apr. 13, 2015; Accepted Jun. 3, 2015
}

biological activities, such as improving the intestinal function in humans and animals (Chen et al., 2001; Ketabi et al., 2011; Yen et al., 2011). Furthermore, IMO are known for their potential to activate the immune system, thereby enhancing resistance to diseases and improving lipid metabolism (Wang et al., 2001; Mizubuchi et al., 2005; Li et al., 2009b).

Isomaltooligosaccharides have already been shown to have beneficial effects in a number of animal species including broilers (Zhang et al., 2003; Thitaram et al., 2005; Rehman et al., 2009), pigs (Li et al., 2009b; Li et al., 2010), shrimp (Li et al., 2009a; Zhang et al., 2011) and rats (Watanabe et al., 2002; Sung et al., 2004; Mizubuchi et al., 2005). In pigs, the beneficial effects appear to be mediated through enhancement of cell-mediated and humoral immunity of piglets (Li et al., 2010). However, the levels of IMO providing benefits for piglets have been inconsistent, so the optimum level of IMO for weaned pigs needs further 
research. The effects of supplementation with IMO in diets on intestinal microflora of weaned pigs and any potential risks in response to increasing inclusion dosages also needs to be studied. Therefore, the objective of the current experiment was to investigate the effects of graded levels of IMO in commercial diets on the performance, immune function, intestinal microflora and intestinal mucosal morphology in weaned pigs.

\section{MATERIALS AND METHODS}

The Institutional Animal Care and Use Committee of China Agricultural University (Beijing, China) approved the procedures used in this experiment. The IMO used in this study was provided by the Baolingbao Biology Company (Shandong, China) and its content of isomaltose, panose and isomaltotriose exceeded $45 \%$ (manufacturer's specifications).

\section{Diets and experimental design}

One hundred and eighty, twenty eight-day-old, crossbred (Duroc $\times$ Large White $\times$ Landrace) weaned pigs, with an initial body weight (BW) of $8.19 \pm 1.45 \mathrm{~kg}$, were blocked by weight, sex, and ancestry and allotted to 1 of 5 dietary treatments in a 28-d experiment. The dietary treatments consisted of a corn-soybean meal based diet or similar diets (including roxarsone and olaquindox) supplemented with $0.2 \%, 0.4 \%, 0.6 \%$, or $0.8 \%$ IMO added at the expense of corn (based on results of a preliminary experiment). During the first 14 days of this experiment, 2,000 ppm zinc oxide was added to all diets. The diets (Table 1) were formulated to meet or exceed nutrient requirements as suggested by the National Research Council (1998).

All pigs were housed indoors in $1.2 \mathrm{~m} \times 2.0 \mathrm{~m}$ concretefloored pens with half of the pen area solid concrete and the remainder plastic slats. The pigs were provided ad libitum access to feed and water throughout the experimental period. The room temperature was maintained at $25^{\circ} \mathrm{C}$ to $27^{\circ} \mathrm{C}$. Each treatment was replicated six times with six pigs (three barrows and three gilts) per pen.

The pigs were individually weighed on $\mathrm{d} 0,14$, and 28 of the experiment and feed consumption was measured per pen at the same time. These values were used to calculate weight gain, feed intake and gain:feed. All piglets were observed for evidence of scouring daily and the diarrhea rate was calculated. Fecal scores were monitored and quantified using a scale ranging from 0 to 3 as described by Marquardt et al. (1999), with $0=$ normally shaped feces, 1 $=$ soft feces, $2=$ mild diarrhea, and $3=$ severe diarrhea. A piglet with a score greater than 1 was regarded as having diarrhea. The diarrhea rate is expressed as the ratio between the number of pigs with diarrhea each day and the total
Table 1. Ingredient composition and nutrient content of basal diet $(\% \text { as fed })^{1,2}$

\begin{tabular}{|c|c|}
\hline Variable & $\%$ \\
\hline \multicolumn{2}{|l|}{ Ingredient (\%) } \\
\hline Corn & 58.52 \\
\hline Dehulled soybean meal ${ }^{3}$ & 16.50 \\
\hline Fish meal & 4.00 \\
\hline Extruded soybean & 10.00 \\
\hline Whey & 4.00 \\
\hline Wheat bran & 1.50 \\
\hline Soybean oil & 1.50 \\
\hline Dicalcium phosphate & 1.60 \\
\hline Limestone & 0.60 \\
\hline DL-methionine (99\%) & 0.04 \\
\hline L-Lysine·HCl (78\%) & 0.34 \\
\hline Sodium chloride & 0.35 \\
\hline Vitamin-mineral premix ${ }^{4}$ & 1.00 \\
\hline Mold inhibitor & 0.05 \\
\hline \multicolumn{2}{|l|}{ Nutrient content ${ }^{5}$} \\
\hline Metabolizable energy $(\mathrm{MJ} / \mathrm{kg})$ & 14.08 \\
\hline Crude protein & 19.21 \\
\hline Crude fiber & 2.88 \\
\hline Ash & 6.14 \\
\hline Calcium & 0.82 \\
\hline Total phosphorus & 0.65 \\
\hline Lysine & 1.32 \\
\hline
\end{tabular}

${ }^{1}$ Isomaltooligosaccharides were simply added to the control diet at concentrations of $0.2 \%, 0.4 \%, 0.6 \%$, and $0.8 \%$ at the expense of corn.

${ }^{2} 2,000 \mathrm{ppm}$ zinc oxide was added to the diets from day 0 to 14 .

${ }^{3}$ Crude protein concentration of dehulled soybean meal is $47.60 \%$.

${ }^{4}$ Provided per kg diet: vitamin A, 9,000 IU; vitamin $\mathrm{D}_{3}, 3,000 \mathrm{IU}$; vitamin E, $20 \mathrm{IU}$; vitamin $\mathrm{K}_{3}, 3.0 \mathrm{mg}$; thiamine, $1.5 \mathrm{mg}$; riboflavin, $4.0 \mathrm{mg}$; pyridoxine, $3.0 \mathrm{mg}$; cobalamin, $0.2 \mathrm{mg}$; biotin, $0.1 \mathrm{mg}$; pantothenic acid, $30 \mathrm{mg}$; nicotinic acid, $15 \mathrm{mg}$; folic acid, $0.75 \mathrm{mg}$; iron (from $\mathrm{FeSO}_{4} \cdot \mathrm{H}_{2} \mathrm{O}$ ), $75 \mathrm{mg}$; copper (from $\mathrm{CuSO}_{4}$ ), $150 \mathrm{mg}$; zinc (from $\mathrm{ZnSO}_{4}$ ), $75 \mathrm{mg}$; manganese (from $\mathrm{MnSO}_{4}$ ), $60 \mathrm{mg}$; iodine (from $\mathrm{KI}$ ), $0.35 \mathrm{mg}$; selenium (from $\mathrm{Na}_{2} \mathrm{SeO}_{3}$ ), $0.3 \mathrm{mg}$; roxarsone, $25 \mathrm{mg}$; olaquindox, $50 \mathrm{mg}$. 5 All nutrient levels except metabolizable energy were chemically analyzed and the results are the means of duplicate determinations.

number of pigs in each group (Zhao et al., 2015). On d 14 and 28 , one pig was randomly chosen from each pen (3 males and 3 females for each treatment) and blood samples were collected from the vena cava cranialis using tubes without anticoagulant. Serum samples were separated by centrifugation at $1,342 \times g$ at $4^{\circ} \mathrm{C}$ for $10 \mathrm{~min}$, and stored at $-20^{\circ} \mathrm{C}$ until needed for analysis.

On d 28, the pigs which were blood sampled were slaughtered. The pigs were stunned by electric shock and then killed by exsanguination. The abdominal cavity was quickly opened to ensure a sterile operation and the ileum and cecum of each pig was isolated, and digesta samples were collected and stored at $-20^{\circ} \mathrm{C}$ until analysis for intestinal microflora. Meanwhile, jejunum and ileum samples were flushed with normal saline to remove the 
digesta and fixed by $10 \%$ formalin buffer for $48 \mathrm{~h}$.

\section{Chemical analysis}

Calcium and total phosphorus in the diets were analyzed according to the methods of the Association of Official Analytical Chemists (2000), while crude protein was measured by the method of Thiex et al. (2002). For dietary lysine determination, feed samples were hydrolyzed with 6 $N \mathrm{HCl}$ for $24 \mathrm{~h}$ (AOAC, 2000). Ash was determined after ignition in a muffle furnace (Nabertherm, Bremen, Germany) at $500^{\circ} \mathrm{C}$ for $4 \mathrm{~h}$. Crude fiber was determined according to the intermediate filtration method (ISO 6865:2000). Amino acids were chromatographically separated and quantified using a Model L-8900 Amino Acid Analyzer (Hitachi, Tokyo, Japan).

Samples were analyzed for serum immunoglobulins, including immunoglobulin A (IgA, which is an antibody that plays a critical role in mucosal immunity), immunoglobulin $\mathrm{M}$ (IgM, which is a basic antibody that is produced by $\mathrm{B}$ cells) and immunoglobulin $\mathrm{G}$ (IgG, which is synthesized and secreted by plasma $B$ cells) and interleukins (ILs), including IL-2 (which is a cytokine signaling molecule in the immune system), IL-6 (which acts as an anti-inflammatory myokine) and IL-8 (which is a chemokine produced by macrophages and other cell types). All kits used in this trial were validated for pig serum (Kit numbers H0003, H0007, H0008, N0048, N0049 and N0050, Sino-uk Institute of Biological Technology, Beijing, China) following the standard procedures described by the manufacturer. Analyses were conducted using a Hitachi Auto-Analyzer (Hitachi 7020) and R-911 Automatic Radioimmunoassay Counter (China University of Technology Industrial Co., Hefei, China).

\section{Microbiological analysis}

Total aerobic bacteria, total anaerobic bacteria, Escherichia coli and Lactobacillus were analyzed by the Tablet Coated Colony Counting Method with three replicates. About $1 \mathrm{~g}$ of ileal and cecal digesta was diluted (1:10) in $9 \mathrm{~mL}$ aliquots of maximum recovery diluents (MRD, Oxoid, Basingstoke, UK), and $0.1 \mathrm{~mL}$ was chosen to spread onto selective agars. The medium for Lactobacillus was de Man, Rogosa and Sharp Agar (Oxoid), and incubation was carried out at $37^{\circ} \mathrm{C}$ overnight (18 to 24 h) in an atmosphere filled with $5 \% \mathrm{CO}_{2}$. The medium for $E$. coli and total aerobic bacteria were MacConkey and Brian Heart Infusion Agars (Oxoid), respectively and incubation was carried out at $37^{\circ} \mathrm{C}$. The total anaerobic bacteria were isolated on Wilkins-Chalgren Anaerobe Agar (Oxoid) with $5 \%$ defibrinated sheep blood, and incubated 18 to $24 \mathrm{~h}$ at $37^{\circ} \mathrm{C}$ in an anaerobic tank (Mitsubishi Gas Chemical Co., Tokyo, Japan). Bacterial counts are expressed as colony- forming unit/g, and presented as $\log _{10}$-transformed data.

\section{Intestinal histological analysis}

Jejunum and ileum samples were dehydrated, paraffin sectioned and hematoxylin-eosin stained, then observed under the microscope to measure villus height and crypt depth with three sections examined for each of three replicates. Histological slices were examined with an Olympus BX51 microscope coupled with an Integrated Digital Imaging Analysis System (Olympus Co., Tokyo, Japan). Images were viewed $(4 \times)$ to observe morphometric parameters of intestinal architecture. Villus height and crypt depths were measured manually. The villus height was denoted by the vertical distance from the crypt opening to the tip of the villus. The crypt depth was represented from the base of the crypt to the level of the crypt opening (Kik et al., 1990).

\section{Statistical analysis}

Analysis of variance was performed using pen means. Differences among treatments were examined using a oneway analysis of variance analysis version 8.0 (SAS Institute Inc., Cary, NC, USA). The linear and quadratic effects of IMO levels were assessed using orthogonal polynomial contrasts. A p-value of less than 0.05 was considered statistically significant, and less than 0.10 was considered a trend.

\section{RESULTS}

\section{Performance}

The effects of different levels of IMO on the performance of weaned pigs are presented in Table 2. From day 0 to 14 , the daily gain $(p<0.05)$ of pigs was linearly increased as the level of IMO supplementation increased, while gain: feed $(\mathrm{p}<0.05)$ was linearly improved. Diarrhea rate showed both a linear $(p=0.05)$ and quadratic $(p=$ $0.05)$ decrease with increasing IMO supplementation. From day 15 to 28 , there was a trend $(p=0.07)$ for increasing weight gain with IMO supplementation increased, but no effect on gain:feed or diarrhea rate of pigs. From day 0 to 28 , weight gain was linearly increased $(p<0.05)$, while gain:feed $(p<0.05)$ was linearly improved and diarrhea rate $(p<0.05)$ was linearly decreased as the IMO level increased.

\section{Immune function}

Table 3 presents the results of the analysis for serum immunoglobulins and ILs of pigs supplemented with different levels of IMO. On d 14, the level of the IgA, IgM and $\operatorname{IgG}$ in the serum of weaned pigs were linearly increased $(\mathrm{p}<0.05)$ with increasing IMO supplementation. IL-6 was linearly $(p<0.05)$ and quadratically $(p<0.05)$ decreased as IMO intake increased. On d 28, the level of 
Table 2. Performance of 28-day old weaned pigs fed diets containing graded levels of isomaltooligosaccharides (d 0 to 28)

\begin{tabular}{|c|c|c|c|c|c|c|c|c|}
\hline \multirow{2}{*}{ Item } & \multicolumn{5}{|c|}{ Level of isomaltooligosaccharides (\%) } & \multirow[t]{2}{*}{ SEM } & \multicolumn{2}{|c|}{ p-value } \\
\hline & 0.0 & 0.2 & 0.4 & 0.6 & 0.8 & & Linear & Quadratic \\
\hline \multicolumn{9}{|l|}{0 to $14 \mathrm{~d}$} \\
\hline Daily gain $(\mathrm{kg})$ & 0.36 & 0.36 & 0.39 & 0.43 & 0.45 & 0.01 & $<0.01$ & 0.45 \\
\hline Daily feed intake $(\mathrm{kg})$ & 0.57 & 0.62 & 0.64 & 0.61 & 0.66 & 0.02 & 0.31 & 0.79 \\
\hline Gain:feed & 0.64 & 0.58 & 0.60 & 0.71 & 0.69 & 0.05 & 0.01 & 0.14 \\
\hline Diarrhea $(\%)^{1}$ & 8.93 & 2.50 & 2.86 & 4.28 & 2.14 & 1.53 & 0.05 & 0.05 \\
\hline \multicolumn{9}{|l|}{15 to $28 \mathrm{~d}$} \\
\hline Daily gain (kg) & 0.45 & 0.47 & 0.49 & 0.56 & 0.56 & 0.02 & 0.07 & 0.92 \\
\hline Daily feed intake $(\mathrm{kg})$ & 0.88 & 0.93 & 0.92 & 0.96 & 0.99 & 0.06 & 0.26 & 0.98 \\
\hline Gain:feed & 0.51 & 0.51 & 0.53 & 0.60 & 0.57 & 0.11 & 0.11 & 0.99 \\
\hline Diarrhea (\%) & 3.21 & 4.64 & 3.57 & 1.78 & 1.43 & 1.50 & 0.21 & 0.48 \\
\hline \multicolumn{9}{|l|}{0 to $28 \mathrm{~d}$} \\
\hline Daily gain $(\mathrm{kg})$ & 0.40 & 0.42 & 0.44 & 0.49 & 0.51 & 0.01 & 0.01 & 0.78 \\
\hline Daily feed intake $(\mathrm{kg})$ & 0.73 & 0.78 & 0.78 & 0.79 & 0.82 & 0.04 & 0.26 & 0.92 \\
\hline Gain:feed & 0.56 & 0.54 & 0.56 & 0.64 & 0.62 & 0.06 & 0.02 & 0.55 \\
\hline Diarrhea (\%) & 6.07 & 3.57 & 3.21 & 3.04 & 1.79 & 1.13 & 0.02 & 0.56 \\
\hline
\end{tabular}

SEM, standard error of the mean.

Values are the means of six replicates.

${ }^{1}$ Diarrhea, the ratio between the number of pigs with diarrhea each day and the total number of pigs in each group.

IL-2 was linearly $(\mathrm{p}<0.05)$ increased as IMO supplementation increased.

Intestinal microflora and intestinal mucosal morphology

The number of total aerobic bacteria, total anaerobic bacteria, E. coli and Lactobacillus in the ileum and cecum contents were unaffected by dietary treatments (Table 4). In addition, no significant difference was found in villus height and crypt depth in the ileum and jejunum, regardless of the dietary level of IMO (Table 5).

\section{DISCUSSION}

Isomaltooligosaccharides are oligosaccharides with interesting nutritional properties, and have been given considerable attention in the scientific field. Li et al. (2009b) indicated that dietary IMO $(0,25,50$, and $75 \mathrm{~g} / \mathrm{kg})$ fed to eight Large White castrated male pigs with an initial bodyweight of $25.6 \pm 1.1 \mathrm{~kg}$ for 8 days did not influence the total tract apparent digestibility of organic matter, crude protein and total ash, so that IMO had limited influence on the performance of growing pigs. However, the results of

Table 3. Serum biochemical measures of weaned pigs fed diets containing graded levels of isomaltooligosaccharides

\begin{tabular}{|c|c|c|c|c|c|c|c|c|}
\hline \multirow{2}{*}{ Item } & \multicolumn{5}{|c|}{ Level of isomaltooligosaccharides (\%) } & \multirow{2}{*}{ SEM } & \multicolumn{2}{|c|}{$\mathrm{p}$-value } \\
\hline & 0.0 & 0.2 & 0.4 & 0.6 & 0.8 & & Linear & Quadratic \\
\hline \multicolumn{9}{|l|}{ d 14} \\
\hline Immunoglobulin A (g/L) & 0.95 & 1.11 & 1.27 & 1.26 & 1.31 & 0.08 & $<0.01$ & 0.21 \\
\hline Immunoglobulin $\mathrm{M}(\mathrm{g} / \mathrm{L})$ & 0.71 & 0.84 & 0.93 & 0.87 & 0.94 & 0.04 & $<0.01$ & 0.13 \\
\hline Immunoglobulin G (g/L) & 6.92 & 8.05 & 8.58 & 8.69 & 8.12 & 0.26 & 0.01 & $<0.01$ \\
\hline Interleukin-2 (ng/mL) & 4.87 & 5.10 & 5.58 & 5.44 & 4.67 & 0.37 & 0.96 & 0.11 \\
\hline Interleukin-6 (pg/mL) & 216.77 & 162.64 & 169.11 & 148.68 & 156.17 & 9.96 & $<0.01$ & 0.03 \\
\hline Interleukin-8 (ng/mL) & 0.70 & 0.67 & 0.63 & 0.61 & 0.66 & 0.05 & 0.39 & 0.34 \\
\hline \multicolumn{9}{|l|}{$\mathrm{d} 28$} \\
\hline Immunoglobulin A (g/L) & 1.19 & 1.10 & 0.92 & 1.10 & 1.07 & 0.09 & 0.46 & 0.20 \\
\hline Immunoglobulin $\mathrm{M}(\mathrm{g} / \mathrm{L})$ & 0.90 & 0.90 & 0.98 & 0.83 & 0.83 & 0.05 & 0.29 & 0.28 \\
\hline Immunoglobulin G (g/L) & 8.36 & 8.22 & 8.64 & 8.40 & 8.40 & 0.25 & 0.76 & 0.72 \\
\hline Interleukin-2 (ng/mL) & 3.63 & 3.57 & 4.17 & 5.69 & 5.67 & 0.34 & $<0.01$ & 0.51 \\
\hline Interleukin-6 (pg/mL) & 143.39 & 136.56 & 141.66 & 158.06 & 147.24 & 11.84 & 0.47 & 0.94 \\
\hline Interleukin-8 (ng/mL) & 0.38 & 0.34 & 0.34 & 0.53 & 0.33 & 0.03 & 0.51 & 0.49 \\
\hline
\end{tabular}

SEM, standard error of the mean.

Values are the means of six replicates. 
Table 4. Intestinal microflora $\left(\log _{10} \mathrm{CFU} / \mathrm{g}\right)$ of weaned pigs fed diets containing graded levels of isomaltooligosaccharides (d 28)

\begin{tabular}{|c|c|c|c|c|c|c|c|c|}
\hline \multirow{2}{*}{ Item } & \multicolumn{5}{|c|}{ Level of isomaltooligosaccharides (\%) } & \multirow{2}{*}{ SEM } & \multicolumn{2}{|c|}{ p-value } \\
\hline & 0.0 & 0.2 & 0.4 & 0.6 & 0.8 & & Linear & Quadratic \\
\hline \multicolumn{9}{|l|}{ Ileum } \\
\hline Total aerobic bacteria & 7.34 & 7.15 & 7.39 & 7.20 & 8.31 & 0.34 & 0.20 & 0.23 \\
\hline Total anaerobic bacteria & 7.90 & 7.30 & 7.75 & 6.93 & 7.35 & 0.33 & 0.31 & 0.66 \\
\hline Lactobacillus & 7.07 & 6.42 & 6.43 & 6.95 & 7.08 & 0.38 & 0.73 & 0.29 \\
\hline Escherichia coli & 5.19 & 4.12 & 5.16 & 3.34 & 3.84 & 0.58 & 0.19 & 0.94 \\
\hline \multicolumn{9}{|l|}{ Cecum } \\
\hline Total aerobic bacteria & 7.67 & 7.44 & 7.54 & 7.26 & 6.62 & 0.34 & 0.12 & 0.49 \\
\hline Total anaerobic bacteria & 7.77 & 7.95 & 8.26 & 7.75 & 6.66 & 0.41 & 0.20 & 0.12 \\
\hline Lactobacillus & 7.73 & 7.83 & 8.17 & 7.76 & 7.47 & 0.21 & 0.54 & 0.17 \\
\hline Escherichia coli & 3.96 & 3.87 & 3.96 & 3.86 & 3.60 & 0.58 & 0.75 & 0.85 \\
\hline
\end{tabular}

SEM, standard error of the mean.

Values are the means of six replicates.

the present study showed that supplementation with $0.6 \%$ and $0.8 \%$ IMO significantly increased weight gain and gain:feed of weaned piglets. The main reason for this discrepancy might be that, the immune system is still developing in weaned pigs and therefore there is more likely to be a response to IMO in younger pigs than older pigs.

Studies concerning for effects of IMO supplementation for weaning piglets are scarce. Zhang et al. (2003) reported that supplementation with IMO enhanced performance only during the initial $3 \mathrm{wk}$, and the final $\mathrm{BW}$ of broilers consuming a diet with $0.3 \%$ IMO was somewhat greater at the end of $7 \mathrm{wk}$. However Thitaram et al. (2005) found that no differences existed in feed intake and feed conversion, although the weight of broilers fed $1 \%$ IMO showed a significant reduction.

Immunoglobulins, also known as antibodies, are large Y-shape proteins that mainly exist in the plasma and are used to identify and neutralize bacteria and viruses (Litman et al., 1993). ILs are a group of cytokines that were first found to be expressed by white blood cells and play an important role in the immune system (Brocker et al., 2010). They could activate and regulate immune cells, including mediating $\mathrm{T}$ and $\mathrm{B}$ cell activation, proliferation and differentiation and play an important role in the inflammatory response. The improvement in pig performance observed in the present experiment is most likely mediated by increases in IgA, IgM and IgG, since the increases of IgA, IgM and IgG indicate the activation of an immune reaction which might lead an improvement in immune status. Wang et al. (2012) reported that IMO had a positive effect on humoral and cell-mediated immunity for host animals. Mizubuchi et al. (2005) reported that the level of IgA in feces was increased when mice were fed a diet supplemented with $20 \%$ IMO (commercially available IMO, which contained $25.6 \%$ IMOs in the dry substance). This is in contrast to a study carried out previously which indicated that level of plasma IgA was not significantly affected in IMO treated rats (Sung et al., 2004).

In general, the main function of antibiotics is correlated with their capacity to eliminate a microorganism. However, toxins are released during the destruction of bacteria, which may, at least temporarily, deteriorate the condition of the microcirculation (AI-Banna et al., 2013). Thus, in this trial, antibiotics (including roxarsone and olaquindox) were added to the diets to enhance disease resistance, the function of IMO were not able to be completely expressed.

Mizubuchi et al. (2005) reported that IL-12 production was increased when mice were fed 20\% IMO. However, there is little literature about IL changes when IMO are fed to pigs. The present study found that IL-6 was decreased in the earlier stage while IL-2 was increased in the later period

Table 5. Intestinal mucosal morphology of weaned pigs fed diets containing graded levels of isomaltooligosaccharides (d 28)

\begin{tabular}{|c|c|c|c|c|c|c|c|c|}
\hline \multirow{2}{*}{ Item } & \multicolumn{5}{|c|}{ Level of isomaltooligosaccharides (\%) } & \multirow{2}{*}{ SEM } & \multicolumn{2}{|c|}{ p-value } \\
\hline & 0.0 & 0.2 & 0.4 & 0.6 & 0.8 & & Linear & Quadratic \\
\hline \multicolumn{9}{|l|}{ Jejunum $(\mu \mathrm{m})$} \\
\hline Villus height & 280 & 294 & 308 & 306 & 290 & 10.41 & 0.41 & 0.20 \\
\hline Crypt depth & 313 & 310 & 286 & 343 & 314 & 14.08 & 0.62 & 0.90 \\
\hline \multicolumn{9}{|l|}{ Ileum $(\mu \mathrm{m})$} \\
\hline Villus height & 341 & 315 & 371 & 347 & 316 & 16.28 & 0.98 & 0.39 \\
\hline Crypt depth & 361 & 400 & 336 & 363 & 351 & 14.09 & 0.51 & 0.82 \\
\hline
\end{tabular}

SEM, standard error of the mean.

Values are the means of six replicates. 
with an increase in IMO supplementation. This is mainly because IL-6 is a factor involved in inflammation, while IL2 is a kind of chemokine which could induce immune function.

Oligosaccharides (e.g. IMO) could inhibit enzymic reactions taking place in the upper part of the gastrointestinal tract, so that intestinal bacterial species might convert oligosaccharides into short-chain fatty acids by expressing specific hydrolases and gas by fermentation in the lower part (Ketabi et al., 2011). They could also promote some specific bacterial species (such as Lactobacilli and Bifidobacteria) selectively in the intestine, thus equilibrating the intestinal microflora (Delzenne, 2003). In the present study, the quantities of total aerobic bacteria, total anaerobic bacteria, E. coli and Lactobacillus in the ileum and cecum contents were unaffected by dietary treatment. This is similar to the finding that the total aerobes, Lactobacillius, and E. coli in the crop and cecum in broilers were not affected by the inclusion of IMO (Zhang et al., 2003). Wang et al. (2012) reported that increases in fecal Lactobacilli were observed when fermented milk supplemented with two probiotic strains and IMO were fed to mice.

Otherwise, IMO products differ substantially in composition, including the proportion of maltose and glucose, or the degree of polymerization, and such differences probably affect their functions on the intestinal microflora. In addition, the villus height and crypt depth of ileum and jejunum were not affected by the addition of IMO in this trial. The main reason might be that in the interaction of gut microflora and animal digestive enzymes (especially isomaltase), IMO were broken down and lost their expected stimulation on the substrate of the gut microflora. In conclusion, under these experimental conditions, a weaned piglet diet supplemented with $0.6 \%$ and $\quad 0.8 \%$ of isomaltooligosaccharide significantly improved piglet weight gain and gain:feed. Adding $0.2 \%$ to $0.8 \%$ IMO reduced the diarrhea rate of weaning piglets aged 0 to 14 days, and enhanced the immune status of pigs after weaning. However, the microflora in the ileum and cecum contents, and jejunum or ileum intestinal mucosa morphology were not affected by IMO addition.

\section{CONFLICT OF INTEREST}

We certify that there is no conflict of interest with any financial organization regarding the material discussed in the manuscript.

\section{ACKNOWLEDGMENTS}

This study was supported by the Ministry of Agriculture (Beijing, China), and we acknowledge the Baolingbao
Biology Company for donation of the isomaltooligosaccharides used in this study.

\section{REFERENCES}

Al-Banna, N. A., D. Pavlovic, M. Gründling, J. Zhou, M. Kelly, S. Whynot, O. Hung, B. Johnston, T. B. Issekutz, H. Kern, V. Cerny, and Ch. Lehmann. 2013. Impact of antibiotics on the microcirculation in local and systemic inflammation. Clin. Hemorheol. Microcirc. 53:155-169.

AOAC. 2000. Official Methods of Analysis. 17th edn. Association of Official Analytical Chemists, Gaithersburg, MD, USA.

Brocker, C., D. Thompson, A. Matsumoto, D. W. Nebert, and V. Vasiliou. 2010. Evolutionary divergence and functions of the human interleukin (IL) gene family. Hum. Genomics 5:30-55.

Chen, H. L., Y. H. Lu, J. J. Lin, and L. Y. Ko. 2001. Effects of isomalto-oligosaccharides on bowel functions and indicators of nutritional status in constipated elderly men. J. Am. Coll. Nutr. 20:44-49.

Delzenne, N. M. 2003. Oligosaccharides: state of the art. Proc. Nutr. Soc. 62:177-182.

Goffin, D., N. Delzenne, C. Blecker, E. Hanon, C. Deroanne, and M. Paquot. 2001. Will isomalto-oligosaccharides, a wellestablished functional food in Asia, break through the European and American market? The status of knowledge on these prebiotics. Crit. Rev. Food Sci. Nutr. 51:394-409.

Hayashi, S., T. Hinotani, Y. Takasaki, and K. Imada. 1994. The enzymatic reaction for the production of panose and isomaltose by glucosyltransferase from Aureobasidium. Lett. Appl. Microbiol. 19:247-248.

Kaneko, T., T. Matsukubo, T. Yatake, Y. Muramatsu, and Y. Takaesu. 1995a. Evaluation of acidogenicity of commercial isomaltooligosaccharides mixture and its hydrogenated derivative by measurement of $\mathrm{pH}$ response under human dental plaque. Biosci. Biotechnol. Biochem. 59:372-377.

Kaneko, T., A. Yokoyama, and M. Suzuki. 1995b. Digestibility characteristics of isomaltooligosaccharides in comparison with several saccharides using the rat jejunum loop method. Biosci. Biotechnol. Biochem. 59:1190-1194.

Ketabi, A., L. A. Dieleman, and M. G. Gänzle. 2011. Influence of isomalto-oligosaccharides on intestinal microbiota in rats. J. Appl. Microbiol. 110:1297-1306.

Kik, M. J., J. Huisman, A. F. van der Poel, and J. M. Mouwen. 1990. Pathologic changes of the small intestinal mucosa of pigs after feeding Phaseolus vulgaris beans. Vet. Pathol. 27:329-334.

Kohmoto, T., K. Tsuji, T. Kaneko, M. Shiota, F. Fukui, H. Takaku, Y. Nakagawa, T. Ichikawa, and S. Kobayash. 1992. Metabolism of 13C-Isomaltooligosaccharides in healthy men. Biosci. Biotechnol. Biochem. 56:937-940.

Li, J., B. Tan, and K. Mai. 2009a. Dietary probiotic Bacillus OJ and isomaltooligosaccharides influence the intestine microbial populations, immune responses and resistance to white spot syndrome virus in shrimp (Litopenaeus vannamei). Aquaculture 291:35-40.

Li, Y. J., G. Y. Zhao, W. Du, and T. J. Zhang. 2009b. Effect of dietary isomaltooligosaccharides on nutrient digestibility and concentration of glucose, insulin, cholesterol and triglycerides 
in serum of growing pigs. Anim. Feed Sci. Technol. 151:312315.

Li, M., W. L. Liu, G. Y. Zhao, L. M. Yu, Y. H. Wu, Y. F. Wu, Z. Q. Pan, and Z. H. Shen. 2010. Effect of different oligosaccharides on immunity and production performance of piglets. Anim. Husb. Feed Sci. Z2:9-11.

Litman, G. W., J. P. Rast, M. J. Shamblott, R. N. Haire, M. Hulst, W. Roess, R. T. Litman, K. R. Hinds-Frey, A. Zilch, and C. T. Amemiya. 1993. Phylogenetic diversification of immunoglobulin genes and the antibody repertoire. Mol. Biol. Evol. 10:60-72.

Marquardt, R. R., L. Z. Jin, J. W. Kim, L. Fang, A. A. Frohlich, and S. K. Baidoo. 1999. Passive protective effect of egg-yolk antibodies against enterotoxigenic Escherichia coli K88+ infection in neonatal and early-weaned piglets. FEMS Immunol. Med. Microbiol. 23:283-288.

Mizubuchi, H., T. Yajima, N. Aoi, T. Tomita, and Y. Yoshikai. 2005. Isomalto-oligosaccharides polarize Th1-like responses in intestinal and systemic immunity in mice. J. Nutr. 135:28572861.

National Research Council. 1998. Nutrient Requirements of Swine. 10th Ed. National Academy Press, Washington, DC, USA.

Rehman, H., W. Vahjen, A. Kohl-Parisini, A. Ijaz, and J. Zentek. 2009. Influence of fermentable carbohydrates on the intestinal bacteria and enteropathogens in broilers. Worlds Poult. Sci. J. 65:75-90.

Sung, H. Y., H. J. Jeong, and Y. S. Choi. 2004. Effects of fructans and isomaltooligosaccharide on large bowel mass and plasma and fecal immunoglobulin A in rat. Nutr. Sci. 7:196-200.

Thiex, N. J., H. Manson, S. Andersson, and J. A. Persson. 2002. Determination of crude protein in animal feed, forage, grain, and oilseeds by using block digestion with a copper catalyst and steam distillation into boric acid: collaborative study. J. AOAC Int. 85:309-317.

Thitaram, S. N., C. H. Chung, D. F. Day, A. Hinton Jr, J. S. Bailey, and G. R. Siragusa. 2005. Isomaltooligosaccharide increases cecal Bifidobacterium population in young broiler chickens. Poult. Sci. 84:998-1003.
Vetere, A., A. Gamini, C. Campa, and S. Paoletti. 2000. Regiospecific transglycolytic synthesis and structural characterization of 6-O-alpha-glucopyranosyl-glucopyranose (isomaltose). Biochem. Biophys. Res. Commun. 274:99-104.

Wang, H. F., P. S. Lim, M. D. Kao, E. C. Chan, L. C. Lin, and N. P. Wang. 2001. Use of isomalto-oligosaccharide in the treatment of lipid profiles and constipation in hemodialysis patients. J. Ren. Nutr. 11:73-79.

Wang, S., H. Zhu, C. Lu, Z. Kang, Y. Luo, L. Feng, and X. Lu. 2012. Fermented milk supplemented with probiotics and prebiotics can effectively alter the intestinal microbiota and immunity of host animals. J. Dairy Sci. 95:4813-4822.

Watanabe, T., M. Watanabe, and K. Seiji. 2002. Prophylactic or ameliorating agent for immunological dysfunction, prophylactic or ameliorating agent for microbism, tumor immunological enhancer and prophylactic or ameliorating agent for in vivo various dysfunctions and functional food comprising alpha-1,6-bonded chain glucose oligomer as active ingredient. Japanese Patent, JP 2002161039.

Yen, C. H., Y. H. Tseng, Y. W. Kuo, M. C. Lee, and H. L. Chen. 2011. Long-term supplementation of isomaltooligosaccharides improved colonic microflora profile, bowel function, and blood cholesterol levels in constipated elderly people: a placebo-controlled, diet-controlled trial. Nutrition 27:445-450.

Zhang, W. F., D. F. Li, W. Q. Lu, and G. F. Yi. 2003. Effects of isomalto-oligosaccharides on broiler performance and intestinal microflora. Poult. Sci. 82:657-663.

Zhang, Q., B. Tan, K. Mai, W. Zhang, H. Ma, Q. Ai, X. Wang, and Z. Liufu. 2011. Dietary administration of Bacillus (B. licheniformis and B. subtilis) and isomaltooligosaccharide influences the intestinal microflora, immunological parameters and resistance against Vibrio alginolyticus in shrimp, Penaeus japonicus (Decapoda: Penaeidae). Aquac. Res. 42:943-952.

Zhao, X., L. Li, Q. Luo, M. Ye, G. Luo, and Z. Kuang. 2015. Effects of mulberry (Morus alba L.) leaf polysaccharides on growth performance, diarrhea, blood parameters, and gut microbiota of early-weanling pigs. Livest. Sci. 177:88-94. 